\title{
Effects of sex-sorting and sperm dosage on conception rates of Holstein heifers: Is comparable fertility of sex-sorted and conventional semen plausible?
}

\author{
J. M. DeJarnette ${ }^{\star 1}{ }^{1}$ M. A. Leach, ${ }^{\star}$ R. L. Nebel, ${ }^{\star}$ C. E. Marshall, ${ }^{\star}$ C. R. McCleary, $†$ and J. F. Morenoł \\ *Select Sires Inc., Plain City, OH 43064 \\ †Sexing Technologies Inc., Plain City, OH 43064 \\ ¥Sexing Technologies Inc., Navasota, TX 77868
}

\begin{abstract}
The conception rates of Holstein heifers after AI with 2.1 or $10 \times 10^{6}$ sperm dosages of sex-sorted or conventionally processed sperm were compared. Ejaculates collected by artificial vagina from 8 Holstein sires were cryopreserved at either 2.1 or $10 \times 10^{6}$ sperm per dose with or without sorting to $90 \%$ purity for X-chromosome-bearing spermatozoa using flow cytometry. All treatments were processed in an egg-yolk (20\%), TRIS, glycerol (7\%) extender and packaged in color-coded $0.25-\mathrm{mL}$ French straws. Straws $(\mathrm{n}=350$ straws/treatment per sire) were packaged and distributed in aliquots of 12 (3 straws of each treatment) to 51 herds of Holstein heifers. Straw color was recorded in the on-farm record keeping system at the time of AI and retrieved by electronic download. In total, 9,172 services were recovered, providing a mean sample size of $287 \pm 3.5$ services/sperm dose per semen type within sire (range: 248 to 318 ). Conception rates were influenced by the main effects of herd, sire, semen type, sperm dosage, and service number. The herd by sperm dosage interaction was the only interaction determined to be significant and implies that some herds (technicians) are more proficient than others at maintaining high levels of conception with decreased sperm dosages. Across herds and sires, the conception rates of each semen type by sperm dosage combination were as follows: $2.1 \times 10^{6}$ sex-sorted, $38 \%, \mathrm{n}=2,319 ; 10 \times 10^{6}$ sexsorted, $44 \%, \mathrm{n}=2,279 ; 2.1 \times 10^{6}$ conventional, $55 \%$, $\mathrm{n}=2,282$; and $10 \times 10^{6}$ conventional, $60 \%, \mathrm{n}=2,292$. The observation that conception rates of sex-sorted semen were improved by the $10 \times 10^{6}$ sperm dosage is encouraging toward the prospectus of development of a commercially available sex-sorted product with im-
\end{abstract}

Received January 26, 2011.

Accepted March 13, 2011.

${ }^{1}$ Corresponding author: jmdejarnette@selectsires.com proved conception potential over existing technology. However, the failure of the $10 \times 10^{6}$ sex-sorted sperm dosage to achieve conception rates comparable to either dosage of conventional semen is somewhat discouraging toward the plausibility of comparable conception rates to conventional semen in the absence of major technological advances in efficiency of sperm sorting or cryopreservation.

Key words: sex-sorted sperm, sperm dosage, flow cytometry, conception rate

\section{INTRODUCTION}

Accurate identification of $\mathrm{X}$ and $\mathrm{Y}$ chromosomebearing sperm populations using flow cytometry was first reported by Garner et al. (1983). The technology was later validated by Johnson et al. (1989) with the live birth of offspring of the predicted sex. Continued research documented the ability of flow sorting to consistently produce approximately $90 \%$ sex bias among offspring of cattle (Seidel et al., 1999; Schenk et al., 1999) and facilitated eventual commercial adaptation. Despite successes, the highly invasive nature of the sex-sorting procedure has detrimental effects on sperm viability and quality (Seidel and Garner, 2002; Seidel, 2007). Furthermore, the expense and efficiencies dictate that commercial application of sex-sorted sperm is only economically viable through use of extremely low sperm number dosages (Amann, 1999; Seidel, 2007). Therefore, commercial application has been largely limited to $2.1 \times 10^{6}$ sex-sorted sperm dosages with targeted application in virgin heifers to capitalize on the greater opportunity for conception and positive return on investment (as compared with cows) to the producer.

The relationship of sperm numbers and semen quality to fertility using conventional semen were first described by Salisbury and VanDemark (1961). Later studies (Den Daas et al., 1998; Saacke et al., 2000) have clearly documented that some differences in fertility 
potential among males (or semen samples) are responsive to increased sperm dosage (compensable), whereas others are not (uncompensable). In an extensive sperm dosage trial across 20 mature AI sires, Den Daas et al. (1998) concluded that the compensable component is largely satisfied in the average sire at total sperm dosages of approximately $4.0 \times 10^{6}$ (range: 1 to $11 \times$ $10^{6}$ sperm/dose).

Based on results of developmental research (Seidel, 2007; Schenk et al., 2009), it was anticipated that commercial application of $2.1 \times 10^{6}$ dosages of sex-sorted sperm in Holstein heifers would yield conception rates that are approximately 75 to $80 \%$ of those obtained with conventional semen. Documentation of field results in the United States has been largely consistent with those expectations (DeJarnette et al., 2009). With the prospects for improved efficiency of sex-sorting procedures (Sharpe and Evans, 2009), higher sperm dosages for commercial application may become a realistic possibility. DeJarnette et al. (2008, 2010) observed marginal improvements in conception rates of some sires after AI with sex-sorted dosages in the range of 3.5 to $5.0 \times 10^{6}$, which suggests at least a portion of the decrease in conception rates with sex-sorted sperm may be compensable. In contrast, a comparison of nonreturn rates achieved with $2 \times 10^{6}$ sperm dosages of sex-sorted and conventional semen with those obtained using $15 \times 10^{6}$ conventionally processed sperm implies a portion of the decrease in conception rates of sexsorted semen is induced by the staining and (or) sorting procedure itself and may not be compensable through increased sperm dosages (Frijters et al., 2009). Studies that have documented compromised embryonic development after AI with sex-sorted semen would tend to support this hypothesis (Sartori et al., 2004; Potter et al., 2009; Larson et al., 2010).

The objectives of the present study were to directly compare the effects of sperm dosage (2.1 vs. $10 \times 10^{6}$ sperm/dose) and sex-sorting (conventional vs. sexsorted) on conception rates of Holstein heifers in a 2 $\times 2$ factorial arrangement. A comparison of conception rates achieved with 2.1 versus $10 \times 10^{6}$ sperm dosages would be indicative of the portion of the decrease in conception rates with sex-sorted semen that is a result of sperm dosage. A comparison of conception rates achieved by sex-sorted and conventional semen within each sperm dosage will be indicative of the portion of the decrease in conception rates with sex-sorted sperm that may be a result of an uncompensable effect of the sorting procedure itself. In essence, the question is asked: considering the existing efficiency of the sex-sorting technology and post-sort semen fertility potential, are comparable conception rates between commercially available sex-sorted and conventional semen plausible?

\section{MATERIALS AND METHODS}

Eight Holstein sires with January 2010 USDA genetic evaluations were selected for this study. To be included, each sire was required to (1) possess breed average or below PTA for calving ease, (2) have a history of producing semen with $>80 \%$ normal sperm morphology, and (3) have a documented normal fertility potential of conventional semen $(\geq-3)$ as assessed by USDA-Animal Improvement Programs Laboratory (AIPL) Sire Conception Rate (SCR). The actual SCR estimates for the sires selected ranged from -0.3 to +3.7 at the initiation of the trial (January 2010 SCR estimates) and from -1.5 to +3.0 at the conclusion of the trial (December 2010 SCR estimates). Ejaculates were collected via artificial vagina and screened for normal sperm morphology at $600 \times$ magnification using differential interference contrast optics after fixing a $10-\mu \mathrm{L}$ sample of neat semen in $0.5 \mathrm{~mL}$ of TALP buffer containing $0.2 \%$ formalin. Abnormalities related to sperm head defects were classified as primary defects and defects involving the sperm tail were classified as secondary abnormalities (Barth and Oko, 1989). Samples with $<80 \%$ normal sperm morphology were rejected. Samples with $\geq 80 \%$ normal sperm morphology were sex-sorted to approximately $90 \%$ purity for X chromosome-bearing sperm according to procedures described previously (Seidel and Garner, 2002; Seidel, 2007). The high sperm number dosages and inefficient nature of the sex-sorting procedure dictated that a split ejaculate technique was not practical for sex-sorted dosages. The $2.1 \times 10^{6}$ sexsorted sperm dosage required 2 to 4 ejaculates per bull and the $10 \times 10^{6}$ sex-sorted sperm dosage required 7 to 9 ejaculates per bull to reach the predefined goal of approximately 350 straws per sperm dosage within sire. A split-ejaculate technique was used for the nonsorted dosages of each sire. Although morphology evaluations were not performed on conventional sperm, ejaculates were collected in a concurrent time period as sex-sorted sperm. All samples were processed in a TRIS-egg yolk, $7 \%$ glycerol extender and packaged in color-coded $0.25-$ $\mathrm{mL}$ French straws to provide AI dosages of 2.1 or 10 $\times 10^{6}$ sperm. Straw color codes were alternated across sires to avoid the potential for perception bias during field use. Straws were frozen in liquid nitrogen vapor at rates within documented tolerance limits (Robbins et al., 1976) before plunging in liquid nitrogen. Sample straws were thawed in water at $37^{\circ} \mathrm{C}$ for 1 min before evaluation for progressive sperm motility. Sperm motility and acrosomal integrity were also evaluated in sample straws after $3 \mathrm{~h}$ of incubation at $37^{\circ} \mathrm{C}$. Motility evaluations were subjective visual estimates of 5 or more random fields of view (avoiding slide perimeter) at $200 \times$ magnification using phase-contrast optics and 
Table 1. Descriptive statistics of semen quality characteristics ${ }^{1}$ of sex-sorted and conventional semen across 8 Holstein sires

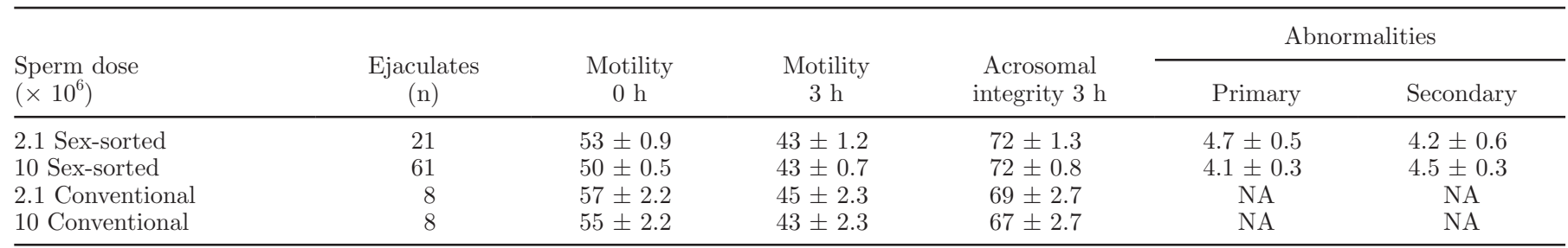

${ }^{1}$ Sperm motility evaluations were performed subjectively at $200 \times$ magnification using phase contrast optics after thawing in a $37^{\circ} \mathrm{C}$ water bath and incubating for 0 or $3 \mathrm{~h}$. Acrosomal integrity evaluations were performed at $400 \times$ magnification using differential interference contrast optics after thawing and incubating sample straws in a $37^{\circ} \mathrm{C}$ water bath for $3 \mathrm{~h}$. Sperm morphology of each ejaculate was screened before sorting and was performed at $600 \times$ magnification using differential interference contrast optics after fixing in a TALP buffer containing $0.2 \%$ formalin. Presort abnormalities of the sperm head and tail were classified as primary and secondary abnormalities, respectively. Ejaculates with $>20 \%$ total sperm abnormalities were discarded before sorting. Although morphology evaluations were not performed (NA, not analyzed) on conventional sperm, ejaculates were collected in a concurrent time period as sex-sorted sperm.

rounded to the nearest $5 \%$. Acrosomal integrity evaluations were conducted at $400 \times$ magnification using differential interference contrast optics (Saacke and Marshall, 1968). The results of post-thaw semen quality evaluations by treatment across sires are presented in Table 1. Post-sort purity of X chromosome-bearing spermatozoa (Welch and Johnson, 1999) averaged $91 \pm$ $0.2 \%$ (range: 85 to $94 \%$ ).

Straws were packaged 12 per cane (3 straws of each dosage) to facilitate balanced and random field use. Semen was distributed in the spring of 2010 to 51 commercial dairy herds, selected based on evidence from on-farm records that the herd had the potential to achieve conception rates $\geq 60 \%$ following the use of conventional semen in virgin heifers. Each herd used a minimum of 36 total doses (9/treatment) across any combination of sires. Recommendations for semen use were to AI females 8 to $12 \mathrm{~h}$ after initial detection of estrus. Synchronization of estrus was acceptable, but use of fixed-time AI in the absence of observed estrus was discouraged. For each AI, straw color was recorded in the on-farm computer records. Pregnancy was diagnosed at 30 to $50 \mathrm{~d}$ after AI according to each farm's standard operating procedures (palpation of uterine contents or ultrasound). Upon completion of the study, an electronic back-up of on-farm records was used to retrieve insemination and pregnancy data. A total of 9,172 services were recovered from the 51 herds (180 \pm 24 services/herd), which provided a mean sample size of $287 \pm 3.5$ services per treatment within sire (range: 248 to 318 ), 2,293 \pm 9 services per treatment across sires, and 1,147 \pm 26 services per sire across treatments. The average age at AI for heifers bred to experimental semen ( $421 \pm 0.5 \mathrm{~d}$ for 7,050 heifers with available birth dates) was not different by sperm dosage or semen type $(P>0.10)$.

Data were analyzed using least squares means ANOVA regression models. All models included the effects of herd, sire, sperm dosage $\left(2.1\right.$ vs. $\left.10 \times 10^{6}\right)$, semen type (sex-sorted vs. conventional), service number (1, 2 , or $\geq 3$ ), and all appropriate 2 - and 3 -way interactions. Season (spring vs. summer) and technician were included as a nested effect within herd. All 2- and 3-way interactions among sire, semen type, and sperm dosage remained in the model irrespective of level of significance, whereas all other interactions and main effects lacking significance $(P>0.10)$ were removed in a backward stepwise manner and data were reanalyzed. All mean comparisons were performed using the Tukey test. A multivariate correlation analysis was performed on the least squares means of each sire by sperm dose by semen type combination to determine the predictive value of sire rankings for conception rates across the various semen types and (or) dosage. All analyses were performed using SAS JMP Statistical Discovery Software (Version 8.0; SAS Institute, Inc., Cary, NC).

\section{RESULTS}

The ANOVA effects of variables included in the final model are presented in Table 2. The main effects of herd, sire, semen type, sperm dosage, and service number were all significant $(P<0.01)$. Herd by sperm dosage was the only significant interaction $(P<0.05)$. The $2.1 \times 10^{6}$ sperm dosages resulted in lower $(P<$ $0.05)$ conception rates than the $10 \times 10^{6}$ sperm dosages in 10 of the 51 herds evaluated $(38 \pm 2.2 \%, \mathrm{n}=113 \pm$ 30 vs. $59 \pm 2.9 \%, \mathrm{n}=115 \pm 30$, respectively), but had no effect $(P>0.05)$ on conception rates in the other 41 herds $(53 \pm 1.7 \%, \mathrm{n}=85 \pm 13$ vs. $55 \pm 1.5 \%, \mathrm{n}=84$ \pm 13 , respectively). Although the 3 -way interaction of sire by sperm dosage by semen type was not significant $(P>0.01)$, these results are nonetheless illustrated in Figure 1. Across herds and sires, the conception rates of all semen type by sperm dosage combinations differed $(P<0.01)$ as follows: $2.1 \times 10^{6}$ sex-sorted, $38 \%, \mathrm{n}=$ 2,$319 ; 10 \times 10^{6}$ sex-sorted, $44 \%, \mathrm{n}=2,279 ; 2.1 \times 10^{6}$ conventional, $55 \%, \mathrm{n}=2,282$; and $10 \times 10^{6}$ conven- 
Table 2. Analysis of variance table of model effects

\begin{tabular}{lrrrr}
\hline Source & df & $\begin{array}{c}\text { Mean } \\
\text { squares }\end{array}$ & F ratio & $P$-value \\
\hline Herd & 50 & 0.94 & 4.0 & $<0.01$ \\
Sire & 7 & 1.70 & 7.2 & $<0.01$ \\
Dosage & 1 & 3.64 & 15.4 & $<0.01$ \\
Semen type & 1 & 59.28 & 250.8 & $<0.01$ \\
Service number & 2 & 3.18 & 13.4 & $<0.01$ \\
Herd $\times$ dosage & 50 & 0.34 & 1.4 & 0.02 \\
Sire $\times$ dosage & 7 & 0.33 & 1.4 & 0.20 \\
Sire $\times$ semen type & 7 & 0.28 & 1.2 & 0.31 \\
Dosage $\times$ semen type & 1 & 0.00 & 0.0 & 0.92 \\
Sire $\times$ dosage $\times$ semen type & 7 & 0.33 & 1.4 & 0.21 \\
\hline
\end{tabular}

tional, $60 \%, \mathrm{n}=2,292$. Across herds, sires, and semen types, conception rates were greater $(P<0.01)$ for 10 than for $2.1 \times 10^{6}$ sperm dosages $(52 \%, \mathrm{n}=4,571$ vs. $47 \%, \mathrm{n}=4,601$, respectively). Across herds, sires, and sperm dosages, conception rates were greater $(P<$ $0.01)$ for conventional than for sex-sorted semen $(58 \%$, $\mathrm{n}=4,574$ vs. $41 \%, \mathrm{n}=4,598$, respectively).

Sire influenced $(P<0.01)$ conception rates within and across all semen types and dosages with a range (across semen type and dosage) of 41 to 53\%. Conception rates obtained by the $10 \times 10^{6}$ conventional sperm dosage were correlated with those obtained by the 2.1 $\times 10^{6}$ conventional sperm dosage $\left(\mathrm{R}^{2}=0.81, P<0.01\right)$ and appeared to be moderately predictive of those ob- tained with the $10 \times 10^{6}$ sex-sorted sperm dosage $\left(\mathrm{R}^{2}=\right.$ $0.48, P=0.06)$. However, no treatment was predictive of the conception rates obtained by individual sire with the $2.1 \times 10^{6}$ sex-sorted sperm dosage $\left(\mathrm{R}^{2}=0.24, P=\right.$ 0.22 vs. $\mathrm{R}^{2}=0.31, P=0.16$ vs. $\mathrm{R}^{2}=0.08, P=0.59$ for $10 \times 10^{6}$ conventional, $2.1 \times 10^{6}$ conventional, and 10 $\times 10^{6}$ sex-sorted dosages, respectively).

Seventy-five percent of all inseminations $(6,842$ of $9,172)$ occurred at first service. Conception rates were greater $(P<0.01)$ for first service AI $(54 \%, \mathrm{n}=6,842)$ than for second service $(49 \%, \mathrm{n}=1,731)$ or for third and greater services $(45 \%, \mathrm{n}=599)$. Most herds used all semen within a single season (spring 2010) and among those herds using semen during the summer

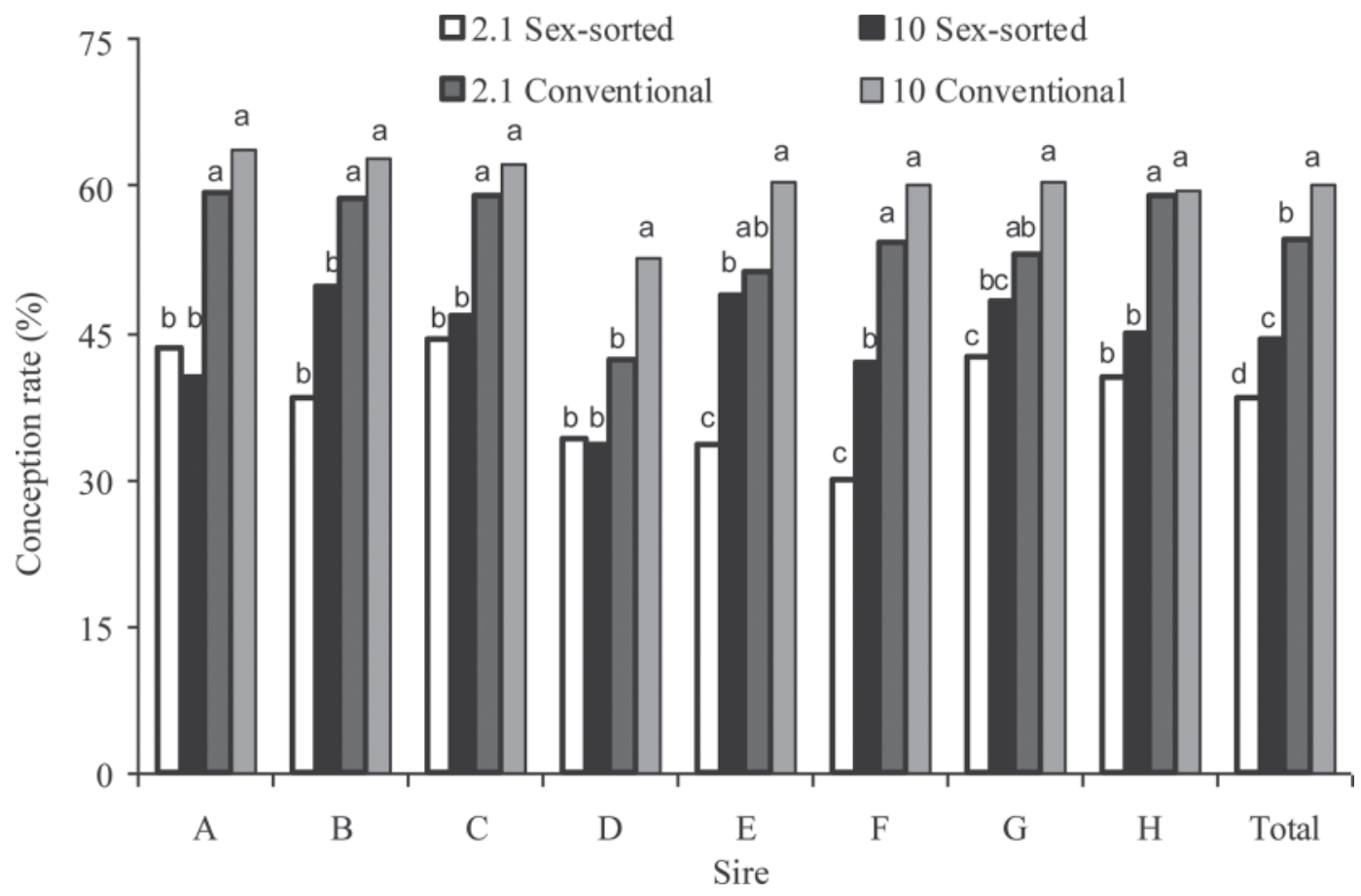

Figure 1. Effects of sire, sperm dosage $\left(2.1\right.$ vs. $\left.10 \times 10^{6}\right)$, and semen type (sex-sorted vs. conventional) on conception rates of virgin Holstein heifers ( $\mathrm{n}=287 \pm 3.5$ services per treatment within sire, range: 248 to 318 ). ${ }^{\text {a-d }}$ Values within sire (or total) lacking common letters differ $(P<$ $0.05)$. Sire effect: $P<0.01$; sperm dosage effect: $P<0.01$; semen type effect: $P<0.01$; sire by sperm dosage by semen type interaction: $P=0.21$. 
months, the nested effect of season within herd was not significant $(P>0.10)$. Technician within herd had no effect on conception rates $(P>0.10)$.

\section{DISCUSSION}

The observation that conception rates were not influenced by any interactions with sire in this study is contradictory to previous research conducted with both conventional (Salisbury and Van Demark, 1961; Den Daas et al., 1998; Saacke et al., 2000) and sex-sorted semen (DeJarnette et al., 2008, 2010). Based on these prior studies, it was anticipated that some sires would be determined to be more (or less) responsive than others to sperm dosage and (or) sex-sorting. Although the pattern of response appears to vary in magnitude for individual sires (Figure 1), the consistency of the main effects within the given sample size of this study appears to have precluded detection of the 3-way interaction of sire by semen type by sperm dosage as significant $(P=0.21)$. The correlation of conception rates among sperm dosages within conventional semen $\left(R^{2}\right.$ $=0.81)$ supports results indicating sire by treatment interactions are not significant. In contrast, the lack of correlation among dosages within sex-sorted semen implies interactions with sire may be occurring but are perhaps masked by sample size or other factors. It is important to note, however, that correlations within such small sample size $(\mathrm{n}=8$ sires $)$ should always be interpreted with caution.

The lack of significance of the sperm dosage by semen type interaction $(P=0.92)$ is particularly notable and implies the sex-sorting procedure itself has a much greater effect on conception rates of sorted semen than does sperm dosage. Across sires, sex-sorted semen decreased conception rates by an almost identical magnitude (16 percentage points) within both sperm dosages (Figure 1) averaging 41 versus 57\%, respectively for sexed and conventional semen across dosages. Similarly, sperm dosage decreased conception rates by an almost identical magnitude (5 percentage points) within both semen types (Figure 1), averaging 47 versus $52 \%$, respectively for 2.1 vs. $10 \times 10^{6}$ sperm dosages across semen types. These observations seem to imply that sperm dosage is not the major limiting factor to the conception potential of sex-sorted semen. To the contrary, it appears that some factor(s) inherent to the sorting procedure itself may be compromising the fertility potential of sorted sperm to a degree that may or may not be compensable with any sperm dosage.

The herd by sperm dosage interaction is likely, at least in part, a function of variation in AI technician proficiency among herds. Within most herds, either a single technician performed all inseminations or if multiple technicians, most had too few services to provide meaningful data for analysis. Therefore, technician could only be analyzed as a nested effect within herd and was not found to be a significant contributor to variation in conception rates. Because herd and technician are typically confounded, the analysis cannot exclude the possibility that technician is one of the major contributors to the variation that is being expressed and detected as a herd effect. Decreased sperm number dosages would be expected to magnify differences in fertility among technicians (herds) because of their competency (or lack thereof) to deliver the sperm dose at a site anterior to the internal cervical os (Senger et al., 1988). Seidel and Schenk (2008) found conception rates of sex-sorted semen were not different after deposition in the uterine body versus ipsilateral or contralateral to the impending ovulatory follicle, which implies that, provided the semen was deposited anterior to the cervix, differences in technician proficiency may be a function of semen handling and maintenance of sperm viability throughout the insemination process. Alternatively, Sá Filho et al. (2010) found conception rates with sex-sorted semen are sensitive to accuracy of estrous detection and appropriate timing of AI. These and other factors may contribute variation in conception rates that is being reflected in the herd (technician) effect. In each case, it is likely that conception rates of the higher sperm dosages will be less sensitive to deviations in semen handling, semen placement, and insemination timing (Salisbury and VanDemark, 1961; Saacke et al., 2000) and, thereby, tend to mask the effect of improper practices. The observation that sperm dosage only affected conception rates in approximately $20 \%$ of herds in this study (10/51) implies that most herds (technicians) were relatively proficient in the handling and delivery of low sperm number dosages. The lack of effect of sperm dosage within some herds may be a type II error as a function of small sample sizes; however, other herds clearly achieved comparable conception rates with the 2 sperm dosages with relatively large sample sizes ( $\mathrm{n}>400$ total services).

Frijters et al. (2009) compared 56-d non-return rates achieved with $2.1 \times 10^{6}$ sex-sorted, $2.1 \times 10^{6}$ conventional, and $15 \times 10^{6}$ conventional sperm dosages and concluded that the sex-sorting procedure had a greater effect on conception rate than did sperm dosage. In that study, sorting was estimated to decrease conception rates by 8.6 percentage points and lower dosage decreased conception rates 5 percentage points. The larger effect of sex-sorting in the present study (16 percentage points) is likely a function of whether or not sex-sorted semen is used as a blind treatment to the inseminator. In typical field use, conception rates of sex-sorted semen are often biased by preferential use 
in females exhibiting definitive signs of estrus, whereby females exhibiting questionable signs of estrus are inseminated with less expensive conventional semen (DeJarnette et al., 2009). Both Frijters et al. (2009) and the present study support the conclusion that a major factor influencing conception rates of sex-sorted semen is not sperm dosage. Although increased sperm dosage holds some promise to improve conception rates of sexsorted semen, it does not appear that sperm dosage, given the current state of sex-sorting technology and efficiency, can realistically be used to raise the level of conception to a point of being comparable with that of conventional semen. Numerous studies have observed decreased fertilization rates (Schenk et al., 2006) and compromised embryonic development after insemination with sex-sorted sperm (Sartori et al., 2004; Potter et al., 2009; Larson et al., 2010), which tends to imply the sorting procedure may impart uncompensable damage to spermatozoal integrity or function. Conversely, Gosálvez et al. (2011) determined the sex-sorting procedure discriminates against sperm containing singlestranded DNA, resulting in an enrichment of sperm possessing normal double-stranded DNA as compared with the unsorted sample. Though this finding tends to argue against uncompensable sperm damage being induced by sex-sorting, it does not definitively exclude the possibility that such may be induced via an alternative mechanism or that the induced alteration is simply unrelated to single versus double-stranded DNA complements. Likewise, the present study does not definitively confirm that some extremely high dosage of sex-sorted sperm cannot compensate for sperm quality deficiencies and raise conception to a level comparable to conventional semen. However, the observation that the $10 \times 10^{6}$ sex-sorted dosage failed to achieve a comparable conception rate to either dosage of conventional sperm tends to imply that commercial availability of a reasonably priced, sex-sorted product that can achieve conception rates comparable to conventional semen is highly unlikely in the absence of major technological advances in sorting procedures. Despite monumental improvements in speed and efficiency of sperm sorting procedures over the last $20 \mathrm{yr}$ (Sharpe and Evans, 2009), present conception rates reported from both research and commercial field applications are only marginally improved from those first reported in early field trials (Seidel et al., 1999). Thus, gains in the decrease of the sperm damage induced by the invasive nature of sperm sex-sorting technology during the same period appear to have been modest at best.

\section{CONCLUSIONS}

Irrespective of sperm dosage, conception rates of virgin heifers were compromised by sex-sorted semen com- pared with conventional semen. The $2.1 \times 10^{6}$ sperm dosages resulted in compromised conception rates compared with $10 \times 10^{6}$ sperm dosage but interacted with herd to have a greater effect in some locations than others, most likely as a function of technician proficiency. Although conception rates of sex-sorted semen were improved by the $10 \times 10^{6}$ sperm dosage, conception rates were not comparable to either dosage of conventionally processed sperm. These observations are encouraging with regard to the possibility for a moderate improvement in the fertility potential of commercially available sex-sorted sorted sperm but somewhat discouraging toward the prospect of a sex-sorted product with a fertility potential comparable to conventional semen, given the existing state of sorting technology.

\section{ACKNOWLEDGMENTS}

The authors thank the owners and employees of the many Select Sires Program for Fertility Advancement (PFA) herds that cooperated in this project, as well as the numerous staff and PFA coordinators for their invaluable assistance. This includes, but is not limited to, Brad Meek (Cache Valley/Select Sires, Logan, UT); Rory White (All West/Select Sires, Turlock, CA); Adam Hahlen (COBA/Select Sires, Columbus, OH); Matt Hershey and Dave Whitlock (Select Sire Power, Rocky Mount, VA); Phil Dieter (East Central/Select Sires, Waupun, WI); Joe Fowler (Southeast/Select Sires, Spring Hill, TN); Butch Lerum (Minnesota/Select Sires, St. Cloud, MN); Julie Ainsworth and Ed Nichols (Northstar Cooperative, East Lansing, MI); Steve Eathington (Prairie State/Select Sires, Hampshire, IL); and Dan Johnson (KABA/Select Sires, Louisville, KY).

\section{REFERENCES}

Amann, R. P. 1999. Issues affecting commercialization of sexed sperm. Theriogenology 52:1441-1457.

Barth, A. D., and J. Oko. 1989. Abnormal Morphology of Bovine Spermatozoa. Iowa State University Press, Ames, IA.

DeJarnette, J. M., C. R. McCleary, M. A. Leach, J. F. Moreno, R. L. Nebel, and C. E. Marshall. 2010. Effects of 2.1 and $3.5 \times 10^{6}$ sex-sorted sperm dosages on conception rates of Holstein cows and heifers. J. Dairy Sci. 93:4079-4085.

DeJarnette, J. M., R. L. Nebel, and C. E. Marshall. 2009. Evaluating the success of sex-sorted semen in US dairy herds from on farm records. Theriogenology 71:49-58.

DeJarnette, J. M., R. L. Nebel, C. E. Marshall, J. F. Moreno, C. R McCleary, and R. W. Lenz. 2008. Effect of sex-sorted sperm dosage on conception rates in Holstein heifers and lactating cows. J. Dairy Sci. 91:1778-1785.

Den Daas, J. H. G., G. De Jong, L. M. T. E. Lansbergen, and A. M. Van Wagtendonk-De Leeuw. 1998. The relationship between the number of spermatozoa inseminated and the reproductive efficiency of individual dairy bulls. J. Dairy Sci. 81:1714-1723.

Frijters, A. C. J., E. Mullaart, R. M. G. Roelofs, R. P. van Hoorne, J. F. Moreno, O. Moreno, and J. S. Merton. 2009. What affects fertility of sexed bull semen more, low sperm dosage or the sorting process? Theriogenology 71:64-67. 
Garner, D. L., B. L. Gledhill, D. Pinkel, S. Lake, D. Stephenson, M. A. Van Dilla, and L. A. Johnson. 1983. Quantification of the X- and Y-chromosome-bearing spermatozoa of domestic animals by flow cytometry. Biol. Reprod. 28:312-321.

Gosálvez, J., M. A. Ramirez, C. López-Fernández, F. Crespo, K. M. Evans, M. E. Kjelland, and J. F. Moreno. 2011. Sex-sorted bovine spermatozoa and DNA damage: I. Static features. Theriogenology $75: 197-205$.

Johnson, L. A., J. P. Flook, and H. W. Hawk. 1989. Sex preselection in rabbits: Live births from $\mathrm{X}$ and $\mathrm{Y}$ sperm separated by DNA and cell sorting. Biol. Reprod. 41:199-203.

Larson, J. E., G. C. Lamb, B. J. Funnell, S. Bird, A. Martins, and J. C. Rodgers. 2010. Embryo production in superovulated Angus cows inseminated four times with sexed-sorted or conventional, frozen-thawed semen. Theriogenology 73:698-703.

Potter, S. R., B. J. Paus, J. M. DeJarnette, and R. L. Nebel. 2009. A case study of experiences with use of sex-sorted semen in superovulated Holstein cows and heifers in a single herd. J. Dairy Sci. 92(E-Suppl. 1):79. (Abstr.)

Robbins, R. K., R. G. Saacke, and P. T. Chandler. 1976. Influence of freeze rate, thaw rate and glycerol level on acrosomal retention and survival of bovine spermatozoa frozen in French straws. J. Anim. Sci. 42:145-154.

Sá Filho, M. F., H. Ayres, R. M. Ferreira, M. Nichi, M. Fosado, E. P. Campos Filho, and P. S. Baruselli. 2010. Strategies to improve pregnancy per insemination using sex-sorted semen in dairy heifers detected in estrus. Theriogenology 74:1636-1642.

Saacke, R. G., J. C. Dalton, S. Nadir, R. L. Nebel, and J. H. Bame. 2000. Relationship of seminal traits and insemination time to fertilization rate and embryo quality. Anim. Reprod. Sci. 60-61:663677.

Saacke, R. G., and C. E. Marshall. 1968. Observations on the acrosomal cap of fixed and unfixed spermatozoa. J. Reprod. Fertil. $16: 511-514$.

Salisbury, G. W., and N. L. VanDemark. 1961. Significance of semen quality. Pages 359-379 in Physiology of Reproduction and Artifi- cial Insemination in Cattle. 1st ed. W. H. Freeman and Co., San Francisco, CA.

Sartori, R., A. H. Souza, J. N. Guenther, D. Z. Caraviello, L. N. Geiger, J. L. Schenk, and M. C. Wiltbank. 2004. Fertilization rate and embryo quality in superovulated Holstein heifers artificially inseminated with X-sorted or unsorted sperm. Anim. Reprod. 1:86-90.

Schenk, J. L., D. G. Cran, R. W. Everett, and G. E. Seidel Jr. 2009 Pregnancy rates in heifers and cows with cryopreserved sexed sperm: Effects of sperm numbers per inseminate, sorting pressure and sperm storage before sorting. Theriogenology 71:717-728.

Schenk, J. L., T. K. Suh, D. G. Cran, and G. E. Seidel Jr. 1999. Cryopreservation of flow-sorted bovine spermatozoa. Theriogenology $52: 1375-1391$

Schenk, J. L., T. K. Suh, and G. E. Seidel Jr. 2006. Embryo production from superovulated cattle following insemination with sexed sperm. Theriogenology 65:299-307.

Seidel, G. E., Jr. 2007. Overview of sexing sperm. Theriogenology 68:443-446.

Seidel, G. E., Jr., and D. L. Garner. 2002. Current status of sexing mammalian spermatozoa. Reproduction 124:733-743.

Seidel, G. E., Jr., and J. L. Schenk. 2008. Pregnancy rates in cattle with cryopreserved sexed sperm: Effects of sperm numbers per inseminate and site of sperm deposition. Anim. Reprod. Sci. 105:129-138.

Seidel, G. E., Jr., J. L. Schenk, L. A. Herickhoff, S. P. Doyle, Z. Brink, R. D. Green, and D. G. Cran. 1999. Insemination of heifers with sexed sperm. Theriogenology 52:1407-1420.

Senger, P. L., W. C. Becker, S. T. Davidge, J. K. Hillers, and J. J. Reeves. 1988. Influence of cornual insemination on conception rate in dairy cattle. J. Anim. Sci. 66:3010-3016.

Sharpe, J. C., and K. M. Evans. 2009. Advances in flow cytometry for sperm sexing. Theriogenology 71:4-10.

Welch, G. R., and L. A. Johnson. 1999. Sex preselection: Laboratory validation of the sperm sex ratio of flow sorted X- and Y-sperm by sort reanalysis for DNA. Theriogenology 52:1343-1352. 